\title{
Knowledge and perception of Ghanaian cocoa farmers on mirid control and their willingness to use forecasting systems
}

Article

Accepted Version

Awudzi, G. K., Asamoah, M., Owusu-Ansah, F., Hadley, P., Hatcher, P. E. and Daymond, A. J. (2016) Knowledge and perception of Ghanaian cocoa farmers on mirid control and their willingness to use forecasting systems. International Journal of Tropical Insect Science, 36 (1). pp. 22-31. ISSN 1742-7584 doi: https://doi.org/10.1017/S1742758415000247 Available at https://centaur.reading.ac.uk/45897/

It is advisable to refer to the publisher's version if you intend to cite from the work. See Guidance on citing.

To link to this article DOI: http://dx.doi.org/10.1017/S1742758415000247

Publisher: Cambridge University Press

All outputs in CentAUR are protected by Intellectual Property Rights law, including copyright law. Copyright and IPR is retained by the creators or other copyright holders. Terms and conditions for use of this material are defined in the End User Agreement. 


\section{CentAUR}

Central Archive at the University of Reading

Reading's research outputs online 
Knowledge and perception of Ghanaian cocoa farmers on mirid control and their willingness to use forecasting systems

3

4

5

6 


\section{Abstract}

3 Annual losses of cocoa in Ghana to mirids are significant. Therefore, accurate timing of

4 insecticide application is critical to enhance yields. However, cocoa farmers often lack

5 information on the expected mirid population for each season to enable them to

6 optimise pesticide use. This study assessed farmers' knowledge and perceptions of

7 mirid control and their willingness to use forecasting systems informing them of

8 expected mirid peaks and time of application of pesticides. A total of 280 farmers were

9 interviewed in the Eastern and Ashanti regions of Ghana with a structured open and 10 closed ended questionnaire. Most farmers (87\%) considered mirids as the most

11 important insect pest on cocoa with $47 \%$ of them attributing $30-40 \%$ annual crop loss to

12 mirid damage. There was wide variation in the timing of insecticide application as a

13 result of farmers using different sources of information to guide the start of application.

14 The majority of farmers (56\%) do not have access to information on the type, frequency

15 and timing of insecticides to use. However, respondents who are members of farmer

16 groups had better access to such information. Extension officers were the preferred

17 channel for information transfer to farmers with $72 \%$ of farmers preferring them to

18 other available methods of communication. Almost all the respondents (99\%) saw the

19 need for a comprehensive forecasting system to help farmers manage cocoa mirids. The

20 importance of accurate timing for mirid control based on forecasted information to

21 farmer groups and extension officers was discussed.

23 Key words: Extension, questionnaire, farmer groups, insecticides, mirid, cocoa 


\section{Introduction}

2 Mirids (Sahlbergella singularis (Haglund), Distantiella theobroma (Distant), Helopeltis

3 spp. and the Bryocoropsis spp.) are economically significant insect pests in cocoa

4 production, particularly in West Africa (Padi and Owusu, 1998, Anikwe et al., 2009),

5 where around $71 \%$ of the world's cocoa is grown. Mirid damage is caused by both

6 adults and nymphs, which pierce their feeding mouth parts into pods, chupons and soft

7 portions of branches. This creates a characteristic vivid circular lesion which turns

8 brown and later black after a couple of hours on pods and elliptical dark lesions on

9 chupons and young stems (Entwistle, 1975). In Ghana, mirid damage is a contributory

10 factor to low yields (Dormon et al., 2007). It is estimated that approximately $30 \%$ of

11 cocoa beans in Ghana is lost to mirids annually (Adu-Acheampong et al., 2014).

12 Control of mirids has mainly been through the use of conventional insecticides applied

13 to mature cocoa with a motorised knapsack spraying machine (Eguagie, 1973, Awudzi

14 et al., 2009, Sonwa et al., 2008). The current recommended time for the start of

15 insecticide application is August since historical reports have shown that the pest

16 increases in numbers in that month (Owusu-Manu, 1995). Recent mirid population

17 studies carried out by Awudzi (2014) suggests that rapid mirid population build-up

18 starts from June and not August. This may be due to the use of hybrid (progenies from

19 bi-parental crosses made in seed gardens) materials producing pods all year round and

20 changes in climate over the years. Adu-Acheampong et al. (2014) also studied the

21 population dynamics of the major mirid species in 1991, 1999, 2003 and 2012 to

22 determine the appropriate timing for the application of insecticides for the control of the

23 pest. They recommended a needs-based system for pest control on cocoa, a shift from

24 the current calendar-based recommendation.

25 Over the years, various insecticides with different active ingredients have been used for

26 mirid control (Entwistle et al., 1959, Eguagie, 1973, Awudzi et al., 2009). Most of the 
1 insecticides used in the 1960s are no longer in use because of their high mammalian

2 toxicity levels and because of new maximum residue levels (MRL) introduced by the

3 European Union (EU) (Raw, 1959, Prins, 1965, Bateman, 2009). Until recently, only

4 three insecticides were recommended for the control of cocoa mirids in Ghana (Awudzi

5 et al., 2009). Their active ingredients are bifenthrin, thiamethoxam and imidacloprid.

6 The Cocoa Research Institute of Ghana (CRIG) conducts research into the safe use of

7 these insecticides and gives recommendations on dosage and application techniques.

8 However, since coverage of extension services in Ghana is limited (Baah, 2002), it is

9 not clear to what extent farmers have access to such information. Lack of adequate

10 information may result in incorrect timing of insecticide applications and mirids

11 numbers reaching their economic thresholds before insecticides are applied.

12 Furthermore, the use of unapproved insecticides, resulting in unacceptable residues in

13 beans and other health problems, can arise if farmers feel their crop is threatened by

14 severe mirid damage. Mirids have developed resistance to some insecticides in the past

15 due to incorrect application (Dunn, 1963, Prins, 1965, Owusu-Ansah et al., 2010). The

16 excessive use of insecticides without any advisory service can impact negatively on the

17 economic viability of cocoa farming as the cost of pesticides may outweigh crop sales

18 as well as destroy beneficial and other non-target organisms (Rejesus et al., 2009).

19 It is not clear whether membership of farmer associations/ cooperatives improves access

20 to information. Most farmers in Ghana do not use research recommendations from

21 CRIG for the control of cocoa mirids because of the difficulty in accessing the

22 information (Gerken et al., 2001). There is evidence to show that farmers get the bulk of

23 their information on how to access and use farming innovations and techniques from

24 other farmers (Pomp and Burger, 1995). There is also a strong peer effect on farmer

25 adoption of innovation in Ghana, with ethnicity and religious affiliation playing a role

26 (Munshi, 2002). In Ghana, a cocoa disease and pest control programme, CODAPEC, 
1 was introduced in 2001 to help manage diseases and pests on cocoa to enhance yield

2 (Asante et al., 2002). This involves the application of recommended insecticides and

3 fungicides on farms at no direct cost to the farmer. Farmers are to ensure that their

4 farms are not weedy and cocoa trees well pruned for good aeration. Water must also be

5 made available for CODAPEC sprayers to make up insecticide and fungicide solutions

6 for application. Even though the programme has helped to increase yields, it is

7 challenged with a late start in some areas and some farmers are not carrying out the

8 needed cultural practices before application is done (Adjinah and Opoku, 2010, Kumi

9 and Daymond, 2015). The perception that some farmers are not always able to afford

10 recommended pesticides to complement CODAPEC's efforts could be another

11 drawback to the pest control programme.

12 In the quest to develop forecasting systems to provide information for effective mirid

13 control, there is a need to investigate farmers' willingness to use such information. The

14 most acceptable mode of conveying this information must also be investigated since the

15 farmer may not access an innovation if the medium of information transfer is not

16 appropriate. A forecasting system for this study is defined as a method of collecting

17 data, processing it and sending the resultant information to the end user (cocoa farmer)

18 for decision making and farm management. For mirid control on cocoa in Ghana, such

19 information might be provided on the basis of the phenology of the crop, climate and/or

20 monitoring of mirid populations.

21 A survey on farmers' access to such information for mirid control, its implications on

22 yield and the acceptability of a forecasting system to inform pest management decisions

23 then becomes necessary.

24 The specific objectives of this study were:

25 1. To assess farmers' knowledge on insecticide use for mirid control. 
12 . To examine whether farmers who are members of farmer association/co-

2 operatives have better access to information on mirid control.

3 3. To test farmers acceptability of a forecasting system to inform pest management decisions for the control of cocoa mirids.

54 To identify the most appropriate medium to send information to cocoa farmers to aid mirid control.

\section{$8 \quad$ Methodology}

\section{Study area}

10 A total of 280 farmers were interviewed from the Ashanti and Eastern Regions of

11 Ghana. District cocoa officers in the regions were contacted to provide names of the 12 major cocoa growing communities. Farmers were then interviewed in these 13 communities.

\section{Design of questionnaire and interview}

16 A structured questionnaire with open and closed ended questions was designed for the 17 study. At the end of each working day, completed questionnaires were cross-checked to ensure they were fully completed. All incomplete or doubtful entries were sent back to

19 the respondent for clarification. This ensured that the views of each respondent were

20 correctly represented, enhancing the reliability of the data collected and information to

21 be deduced from it (Baah, 2006). In most cases, questions were translated to the local

22 language of the area (Twi), taking care not to lose any information. Selection of farmers

23 for interview was not biased towards any gender, religious or political affiliation.

24 Village chiefs, chief farmers and other appropriate opinion leaders in each selected 25 community were briefed on the purpose of the study before any farmer was interviewed.

26 This ensured that farmers received the interviewers through the proper chain of 27 command in each community to enhance the accuracy of information given. The 
1 following variables were used to assess the socioeconomic background of farmers:

2 gender, age, education, marital status, farm ownership status, age and size of farm as

3 well as membership to a farmer group or association. Farmers were also assessed on

4 their knowledge on mirid control, access to information for mirid control, effect of

5 timely insecticide application on mirid numbers and yield, and percentage crop loss to

6 mirid damage. An assessment of insecticides used by farmers was made as well as the

7 timing of applications. Finally, the questionnaire also covered the issue of willingness to

8 use forecasting system for mirid control and the most preferred medium to receive this

9 information. Willingness to use forecasting system was determined with a yes or no

10 question.

12 Reliability of questionnaire

13 A pre-testing exercise was carried out in four communities in the Eastern Region (Nobi,

14 Asafo, Obubanase and Tontro) in order to assess whether there were any ambiguities in

15 the questions. A total of 30 cocoa farmers in these villages were interviewed from the

$1615^{\text {th }}$ November to $6^{\text {th }}$ December, 2011. Any questions that were not easily answered by

17 most farmers due to lack of clarity were modified. The actual surveys with the final 18 questionnaire started on the 26th December, 2011 and were completed on the $6^{\text {th }}$ April, 192012.

20 Data analysis

21 The data was analysed with SPSS statistical package version 16. Variation in responses 22 was analysed to show frequencies and their percentages. Relationship analysis was 23 conducted using a chi-squared test to find out if personal and farm characteristics were 24 associated with farmers' access to information on mirid control, willingness to use a 25 forecasting system for mirid control and the most preferred medium for information transfer. Relationships were also explained between personal/farm characteristics and 27 membership of a co-operative/farmer association. 


\section{Results}

\section{Farmers' personal and farm characteristics}

4 Of the farmers interviewed $76 \%$ were males and $24 \%$ females; their ages ranged from

520 to 80 years. The age group 40-60 years was the most represented accounting for $51 \%$

6 of respondents. In contrast, $18 \%$ of respondents fell within the age group 20 to 40

7 years. A greater percentage of respondents were farm owners (87\%). Respondents with

8 a Middle School Certificate /Junior High School (MSLC/JHS) educational qualification

9 were the most represented (61\%) with $15 \%$ having no formal education. A summary of

10 the personal characteristics of farmers is presented in Table 1.

\section{Farmer associations and farm practices}

12 Most farmers interviewed (71\%) were not part of any farmer association, certification

13 scheme or cooperative society. Approximately 81 farmers are part of a farmer group.

14 Among farmers that were part of a farmer group, $90 \%$ belonged to local farmer associations or cooperative societies. The remainder had some association with Organic Cocoa Certification (4\%) and the Cadbury Livelihoods Programme (now Cocoa Life) $(6 \%)$. The majority of farmers that were part of farmer associations were motivated to do so because of the training they received on Good Agricultural Practice (GAP) (72\%) with $16 \%$ motivated by access to credit. The sources of motivation for joining a farmer association are presented in Figure 1. Access to training was by far the most cited reason for joining an association. Neither gender $\left(\chi^{2}=0.043, \mathrm{p}=0.84\right)$, age of farmer $\left(\chi^{2}\right.$

$22=1.96, \mathrm{p}=0.91)$, marital status $\left(\chi^{2}=4.46, \mathrm{p}=0.35\right)$, educational status $\left(\chi^{2}=7.79, \mathrm{p}=0.17\right)$ or farm ownership $\left(\chi^{2}=1.36, \mathrm{p}=0.71\right)$ had any significant relationship with membership

24 of farmer group, farmer association or cooperative society.

The largest proportion of farmers had hybrid cocoa (progeny of bi-parental crossed produced in seed gardens) on their farms (38\%) whilst $14 \%$ had Amelonado (a 
1 traditional variety), 29\% “Amazon" (early generation hybrids) and 19\% mixed

2 materials. The most frequently cited source of planting materials for respondents is pods

3 from neighbouring farms (48\%) followed by the cocoa seed gardens (39\%) (Figure 2).

4 Cocoa in most farms was not planted in regular lines (78\%), however, the proportion

5 planted in lines was greater amongst those farmers who were members of farming 6 groups $\left(\chi^{2}=6.55, \mathrm{p}=0.01\right)$. Furthermore, members of farmer groups/associations were 7 more likely to grow hybrids $\left(\chi^{2}=8.43, \mathrm{p}=0.04\right)$ and source planting materials from a 8 recommended outlet (i.e. Seed production Unit and CRIG) $\left(\chi^{2}=19.69, \mathrm{p}<0.001\right)$. A

9 relationship was also observed between farmer age and variety grown in that the highest

10 proportion of the farmers that had hybrid cocoa trees on their farms (49\% of farmers)

11 were between age 20 and 40 years $\left(\chi^{2}=12.32, \mathrm{p}=0.05\right)$. A significant association 12 between the age of farm and planting material was observed $\left(\chi^{2}=30.36, p<0.001\right)$ such 13 that a large proportion $(85 \%)$ of more recently established farms ( $>20$ years) were 14 planted with hybrid trees sourced from recommended outlets (e.g. seed production units 15 and CRIG). Furthermore, a greater proportion of trees were planted in lines (as opposed 16 to uneven planting) on more recently established farms $\left(\chi^{2}=22.82, \mathrm{p}<0.001\right)(79 \%$ on 17 farms up to 20 years old compared to 26 on farms older than 20 years).

(Table 1 here)

(Figure 1 here)

(Figure 2 here)

\section{Insect pests on cocoa and insecticide application}

23 The majority of farmers $(86.8 \%)$ considered mirids to be the most economically important insect pest on cocoa. A pest gaining importance is Bathycoelia thalassina (stink bug) ('Atee' in the local Twi language), which ranked second with $12 \%$ of

26 farmers considering it as critical to yield losses. A pictorial presentation of respondents' 
1 perception of the most economically important insect pests on cocoa is shown in Figure

23

3

4

5 The vast majority of farmers (92.9\%) applied insecticides for mirid control on their

6 farms. Only $7.1 \%$ did not apply any insecticide mainly due to logistical problems on the

7 farmer's part or on the part of the cocoa pest and disease control (CODAPEC)

8 programme. Confidor (Imidacloprid 200 SL) was the most widely applied insecticide

$9 \quad(50.8 \%$ of respondents) with Actara (Thiamethoxam) used by $25.8 \%$ and Akatemaster

10 (Bifenthrin) by $18.8 \%$ of respondents. A small proportion (1.1\%) of respondents used

11 unapproved insecticides for mirid control and 3.5\% of respondents (under Organic

12 certification) applied crude aqueous neem extract. The vast majority (93.9\%) of

13 respondents graded the performance of insecticides applied as very effective against

14 mirids whilst $3.8 \%$ and $2.3 \%$ judged them as providing no change or as not being

15 effective against the pests respectively. Among respondents who recalled the timing of

16 insecticide application, August was the month in which most respondents $(30.3 \%)$

17 applied insecticides for the first time in the season with $19.2 \%$ spraying in September,

$18 \quad 11.9 \%$ in June and $7.3 \%$ in May (Figure 4).

19

20 The issues that inform farmers' choice of the month to start insecticide application for

21 mirid control are summarised in Table 2. The start of the CODAPEC spraying 22 programme was the most cited reason (49.2\% of respondents), whilst $19.4 \%$ farmers

23 also relied on the visual presence of mirids to start insecticide application. The majority 24 of farmers $(90.8 \%)$ interviewed stated that they had benefited from the CODAPEC
(Table 2 here) 


\section{Source of information on insecticide usage}

2 Less than half of the farmers interviewed (43.6\%) received information on which

3 insecticide to use for mirid control. Amongst these, $85.2 \%$ of them did so through

4 extension officers, $4.1 \%$ from CRIG, $4.9 \%$ from certification officers and the rest

$5(5.8 \%)$ received their information from other farmers and input suppliers. In terms of

6 timing of insecticide application $43.6 \%$ of farmers received information on the

7 appropriate time of the year to apply insecticide. Amongst this group of farmers, $86.1 \%$

8 cited extension officers as the source of that information whilst fewer farmers cited

9 certification officers (5.7\%), CRIG (3.3\%) and contributions by other farmer and

10 suppliers (4.9\%). With regards to the frequency of insecticide application, $43.9 \%$ of

11 farmers were able to access information and, amongst these most farmers $(86.1 \%)$

12 received such information from extension officers. Amongst those farmers who had

13 access to information on which insecticide to use as well as timing and frequency of

14 application the vast majority (95.9\%) found the information useful for mirid control.

15 Detail of farmers' sources of information on insecticide use is presented in Table 3. A

16 significant relationship was observed between a farmer's age and access to information

17 on insecticide use. Farmers between 20 to 40 years were more exposed to information

18 on insecticide use ( $57 \%$ of farmers: $\left.\chi^{2}=5.65, \mathrm{p}=0.05\right)$ than any other age group.

19 Furthermore, ability to access information on which insecticide to use was significantly

20 greater for those farmers in a group or association $\left(\chi^{2}=75.58, \mathrm{p}<0.001\right)$. This was also

21 the case regarding information on time of application $\left(\chi^{2}=75.56, \mathrm{p}<0.001\right)$, frequency

22 of application $\left(\chi^{2}=78.76, \mathrm{p}<0.001\right)$ as well as factors influencing the choice of the when

23 to start insecticide application for mirid control $\left(\chi^{2}=41.77, \mathrm{p}<0.001\right)$. Farmers who are

24 members of farmer associations rely mostly on CRIG recommendations and the level of

25 mirid damage in farms to decide on the month to start insecticide application while non-

26 members rely to a greater extent on the start of the CODAPEC spraying programme. 
1 Meetings held by farmer groups become the platform for extension service personnel to

2 be invited to provide such information or give training. Cocoa farmers acknowledged

3 the importance of timely application of insecticide as $97.1 \%$ of them suggested

4 increased mirid damage and a reduction in yield when insecticide is applied later than

5 required. The largest proportion of farmers (47\%) attributed $30-40 \%$ of cocoa losses to

6 mirid damage annually.

(Table 3 here)

\section{$8 \quad$ Forecasted system}

9 Almost all farmers interviewed (99.6\%) thought that it would be useful to have

10 forecasting systems to inform them of expected mirid peak periods in each year, which

11 insecticides to use, time to start insecticide application and the required frequency of

12 applications. The reason cited by farmers for the need for an information system are as

13 follows (with corresponding percentages): to enhance production (52.3\%), reduction in

14 mirid damage to cocoa (25\%), broadening farmers' knowledge base on mirid control

$15(15.9 \%)$ and for effective control of mirids (6.8\%). Most farmers (70\%) preferred to

16 receive information on mirid control on a quarterly basis. Some $14.6 \%$ preferred to be

17 informed twice a year with $10 \%$ as and when necessary. The majority of farmers

$18(89.6 \%)$ would be willing to support (financially) a forecasting service if COCOBOD is

19 unable to meet the full cost.

20 Channel for dissemination of information

21 The majority of farmers interviewed (89.3\%) preferred extension services as the

22 medium to relay information on insecticide usage for mirid control to them. Farmers'

23 preferences for access to information are presented in Table 4. 
1 The main reason for the choice of extension service as the most preferred medium for

2 information transfer was the opportunity to see demonstrations ( $72.1 \%$ of farmers),

3 followed by reliability and ease of access (26.1\%), affordability (1.1\%) and avoidance

4 of language gap problems $(0.7 \%)$.

\section{Discussion}

6 Access to information is a key component that enables cocoa farmers to optimise their

7 management and hence increase yields. In many developed countries, both public and

8 private institutions provide farmers with farm management information through a range

9 of systems (Just and Zilberman, 2002). However, in Ghana and other cocoa growing

10 countries in West Africa, the lack of such systems to provide accurate, easily accessible

11 and timely information on pest management presents a number of challenges to cocoa

12 farmers. Farmers sometimes rely on 'word-of-mouth' for decision making which may

13 not be accurate or timely.

14 Forecasting systems consist mainly of data that have been processed to be meaningful to

15 the end user (Acebedo et al., 2008). A forecasting system is therefore a system to collect

16 data, process it to be meaningful and transmit it to the end user (cocoa farmer) for

17 effective decision making and farm management. The study therefore examined the

18 willingness of cocoa farmers in Ghana to use such forecasting systems for mirid control

19 and whether particular groups of farmers are more willing to take up such information.

20 The survey showed that cocoa farming is a male dominated profession. This is the case

21 for most cocoa growing countries in West Africa (Olujide and Adeogun, 2006). Most

22 cocoa farmers interviewed were also over the age of 40 highlighting the need to

23 encourage young people to take up cocoa farming as a profession. The aging farmer

24 population has sometimes led to cocoa farms being abandoned after the death of their owners (Asante et al., 2002). The current economic status of cocoa farmers in Ghana 
1 makes it difficult for them to encourage their children to take up the enterprise after

2 school since they are often more interested in non-agricultural employment in the cities.

3 This study also showed that farmers' age is very important when it comes to adopting

4 innovative practices; most of the farmers between 20 and 40 years had more access to

5 information on insecticide use and have adopted the use of hybrid materials and

6 planting them in lines on their farms. The results suggest that more effort needs to be

7 made to encourage older farmers to adopt new innovations.

8 West Africa is responsible for approximately 71\% of world cocoa (ICCO, 2012/13),

9 produced mostly by smallholder farmers as exemplified in the present study $(70 \%$ of

10 farms surveyed were less than 1.5 hectares). Many of these smallholder farms are aging

11 and require some rehabilitation or replanting. The study showed that at least $14 \%$ of

12 farmers still grow traditional Amelonado cocoa, and less than half grow the

13 recommended hybrid varieties. Replacing old, low yielding trees with recommended

14 hybrid materials is an important step to enhanced cocoa production. However, when

15 replanting, nearly half the respondents obtained seed from neighbouring farms. A

16 survey of cocoa seed gardens in Cameroon, Ghana and Nigeria suggests that the

17 majority of farmers used seeds from neighbours' farms due to lack of nearby seed

18 gardens (Asare et al., 2010). The amount of hybrid seed available from seed gardens to

19 cocoa farmers in Ghana is considered inadequate. Asare et al. (2010) estimate that less

20 than $60 \%$ of the demand for seed for new planting material in Ghana is met by seed

21 gardens. As a result, cocoa farmers are using inappropriate, segregating F3 and F4 seed

22 populations as planting materials. Farmers' lack of understanding of the development of

23 hybrid materials is also a reason for the use of segregated seeds. It is therefore important

24 that new planting materials are made available for replanting through increased

25 availability of hybrid seed/ seedlings from seed gardens in Ghana. 
1 Replacing old materials with high yielding varieties will only produce higher yields if

2 pest and disease challenges of the crop are well managed. Cocoa mirids have been cited

3 as the most important insect pest on cocoa in Ghana (Awudzi et al., 2009, Padi, 1997,

4 Owusu-Manu, 1995). The majority of farmers (87\%) interviewed agreed with this

5 assessment with $47 \%$ of farmers attributing a $30-40 \%$ loss in yield to mirids. This

6 perception is similar to published estimates of losses to mirids in the region of $30 \%$

7 (Owusu-Manu, 1995). Over 90\% of farmers applied insecticides in the 2011/2012 cocoa

8 season. The month during which most respondents (30.3\%) first applied insecticides for

9 mirid control was August. This could be due to factors such as the start of the

10 CODAPEC spraying programme (which is scheduled to start in August) or the

11 perceived increase in mirid numbers and damage in farms. The results of the survey

12 showed that, most farmers rely on the start of the CODAPEC programme $(49.2 \%)$,

13 presence of mirids $(19.4 \%)$ and the weather $(10.1 \%)$ to decide on the month to first

14 apply insecticides each season. It was noted that not all farmers follow

15 recommendations or labelled instructions on recommended insecticides. There is the

16 perception by some farmers that the higher the concentration of insecticide solutions,

17 the greater the efficacy (Matthews et al., 2003). The inconsistencies in the dosages of

18 insecticides applied in cocoa farms could increase the risk of mirid resistance to

19 approved insecticides. Effective farmer education on pest identification and accessibility

20 to information on insecticide usage is therefore important.

21 The survey also showed that less than $30 \%$ of farmers' interviewed were members of a

22 farmer or cooperative groups. Farmers associations like cocoa Abrobopa, Kuapa

23 Kookoo and the Cadbury Livelihood Programme (now Cocoa Life) are training farmers

24 on best cultural practices. These practices are geared towards improving farm sanitation

25 to minimize pest and disease damage to enhance yield. Some farmer associations also support farmers with inputs such as fertilizers, insecticides and fungicides on credit 
1 (Baah, 2008). Recent certification of cocoa has led to the development of certification

2 schemes such as Rainfall Alliance, Naturland (organic certification) and UTZ

3 certification who train farmers to meet particular standards. According to Baah (2008),

4 farmer associations have helped the expansion and growth of the cocoa industry in

5 Ghana through farmer training. In this study, most farmers who were members of

6 farmer associations also had easy access to information on insecticide use, time of

7 application and frequency of applying insecticides for mirid control. This study also

8 demonstrated the effectiveness of membership of a farmer group in the adoption of

9 innovations such as the use of hybrid materials, planting in lines and sourcing planting

10 materials from recommended bodies, thereby demonstrating the potential of such

11 associations to play a part in increasing cocoa production. Another reason why

12 encouraging the formation of farmer groups across the entire cocoa landscape could

13 boost production is that most farmers are able to learn and adapt new farm practices

14 easily from fellow farmers who can recognize their needs (Baah, 2008). Membership of

15 a farmer association was closely related to the farmer's choice of month to start

16 insecticide application, with a greater proportion relying on the presence of mirids

$17(21 \%)$ and the Cocoa Research Institute of Ghana (CRIG) recommendations (16\%)

18 compared to those who were not part of a farmer group who relied mainly on the start of

19 the cocoa pest and disease control (CODAPEC) programme. Relying on the start of the

20 CODAPEC programme is not the best approach as the start of the programme may be

21 delayed due to logistical problems such as late arrival of pesticides at various districts

22 and the frequent breakdown of spraying machines (Baffoe-Asare et al., 2013).

23 Significant losses of cocoa can occur due to mirid damage when there is a delay in the

24 start of the programme.

25 An overwhelming response from farmers for the need for a forecasting system for mirid

26 control was demonstrated. Farmers were aware of the difficulty in managing cocoa 
1 mirids and the need for accurate information for effective pest management.

2 Information could be sent to farmers on when to apply recommended insecticides and at

3 what frequency. This would ensure that insecticide application is carried out on a need-

4 based system and not the blanket application system currently in use. Such an approach

5 would help reduce insecticide residue problems in cocoa beans as well as addressing

6 health issues related to insecticide use. The fact that farmers were willing to pay

7 towards an information system is indicative of the importance that they attach to a more

8 targeted mirid control system. Farmers' willingness to help sustain a forecasting system

9 for mirid control stems from the need to get accurate information for mirid management

10 to produce more and to contribute to the enhancement of their living conditions and also

11 ensure that a programme of that nature does not eventually "breakdown" due to national

12 budgetary constraints.

13 Extension services appeared to be the most preferred means of information and

14 technology transfer to cocoa farmers in Ghana with $89.3 \%$ of respondents opting for

15 this route. For extension to be effective, extension services need to develop farmer

16 centred information technologies which are interactive. Furthermore, Adu-Acheampong

17 et al. (2014) point to the relatively low number of extension officers currently in the

18 cocoa sector in Ghana. Even though radio is reported to be the most important medium

19 for communicating with rural populations in developing countries (Odame and Kassam,

20 2002), it is limited in its "one-way" communication channel. In Ghana, this limitation

21 has been improved with farmers calling into radio programs for clarification when

22 necessary. Recently, the Ghana Cocoa Board in partnership with Cadbury, "Kuapa

23 Kookoo" (a co-operative) and West Africa Fair Fruits Limited has agreed to support

24 cocoa extension as well as implement interventions to enhance the livelihood of cocoa

25 growing communities in Ghana (Government of Ghana, 2011). Cocoa extension in

26 Ghana has also been revived under the Cocoa Health and Extension Division (CHED) 
1 (a division of the Ghana Cocoa Board); extension could be used as a tool in any

2 information system to disseminate information on mirid management to cocoa farmers.

3 From the results of the survey, the success and adoption of any information system

4 depends critically on the inclusion of extension services and local famer organizations.

5 The CODAPEC programme in Ghana could further be enhanced with the addition of an

6 information system to provide forecasted information on expected pest situations to

7 improve the effectiveness of the programme.

\section{Conclusion}

9 Cocoa mirids continue to be the most important insect pest on cocoa in Ghana and other

10 cocoa-producing countries in West Africa. Control has mainly been achieved with

11 blanket application of conventional insecticides based on a specific calendar date. This

12 has led to the development of residue problems as well as changes in the status of some

13 pests which hitherto were regarded as minor. The root of this problem is inadequate

14 farmer knowledge on approved insecticides, timing and the frequency of application

15 within a growing season. It is clear from this study that even though information on

16 insecticide use and mirid management on cocoa is available, many farmers have little or

17 no access to such information. Farmers overwhelmingly accepted (over 99\%) that there

18 is a need for a forecasting system through which they could be informed of mirid

19 activity on their farms as an early warning system and how to effectively manage the

20 pest in a more environmentally sensitive manner. The study has also showed that local

21 farmer groups and extension services will be vital for the success of a forecasting 22 system for mirid control in Ghana. 


\section{Acknowledgment}

2 The authors would like to express their gratitude to Mondelez Inc. and BBSRC,

3 Dorothy Hodgkin Postgraduate Award for sponsoring this study and CRIG management

4 for logistical support. We are also grateful to staff of the Entomology and Social

5 Science divisions of CRIG for their help. This paper is published with the kind

6 permission of the Executive Director of CRIG. 
ACEBEDO, M., TUNEZ, S. \& BIENVENIDO, F. 2008. Information Systems for Pest Control in Protection Agriculture: The Almeria Experience [Online]. CABI. Available: cabi.org/GARA/Full Text PDF/2008/20083298183.pdf [Accessed July 2012 2012].

ADJINAH, K. O. \& OPOKU, I. Y. 2010. The National Cocoa Diseases and Pest Control (CODAPEC): Achievement and Challenges [Online]. Ghana Cocoa Board. Available: http://news.myjoyonline.com/features/201004/45375.asp [Accessed May 6th 2012].

ADU-ACHEAMPONG, R., JIGGINS, J., VAN HUIS, A., CUDJOE, A. R., JOHNSON, V., SAKYI-DAWSON, O., OFORI-FRIMPONG, K., OSEI-FOSU, P., TEIQUARTEY, E., JONFIA-ESSIEN, W., OWUSU-MANU, M., NANA KARIKARI ADDO, M. S., AFARI-MINTAH, C., AMUZU, M., NYARKO EKU-X, N. \& QUARSHIE, E. T. N. 2014. The cocoa mirid (Hemiptera: Miridae) problem: evidence to support new recommendations on the timing of insecticide application on cocoa in Ghana. International Journal of Tropical Insect Science, $34,58-71$.

ANIKWE, J. C., OMOLOYE, A. A. \& OKELANA, F. A. 2009. Field evaluation of damage caused by mirid, Sahlbergella singularis Haglund to selected cocoa genotypes in Nigeria. Bioscience Research Communication, 21, 253-262.

ASANTE, E. G., BAAH, F. \& ADU-ACHEAMPONG, R. 2002. Preliminary report on monitoring of the mass spraying of cocoa in the Eastern Central and Ashanti Regions. Cocoa Research Institute of Ghana, Tafo, Ghana.

ASARE, R., AFARI-SEFA, V., GYAMFI, I., OKAFOR, C. \& J., M. M. 2010. Cocoa seed multiplication: an assessment of seed gardens in Cameroon, Ghana and Nigeria. STCP Working Paper Series 11 (Version August 2010). Sustainable Tree Crops Program. International Institute of Tropical Agriculture, Accra, Ghana.

AWUDZI, G. K. 2014. Development of an information system for mirid attack on cocoa based on the crop status and mirid population monitoring. $\mathrm{PhD}$ Thesis, University of Reading, Reading.

AWUDZI, G. K., ACKONOR, J. B., CUDJOE, A. R., DWOMOH, E. A. \& SARFO, J. E. 2009. Manual for cocoa insect pests, symptoms of their damage and methods of their control, New-Tafo, Akim, Cocoa Research Institute of Ghana.

BAAH, F. 2002. Towards a pluralistic approach in extension service delivery to Ghanaian cocoa farmers Journal of the Ghana Science Association, 4, 78-82.

BAAH, F. 2006. Cocoa cultivation in Ghana: An analysis of farmers' information and knowlegde systems and attitudes. $\mathrm{PhD}$, University of Reading.

BAAH, F. 2008. Harnessing farmer associations as channels for enhancing management of cocoa holdings in Ghana. Scientific Research and Essay, 3, 395-400.

BAFFOE-ASARE, R., ABREFA DANQUAH, J. \& ANNOR-FREMPONG, F. 2013. Socioeconomic Factors Influencing Adoption of Codapec and Cocoa High-tech 
Technologies among Small Holder Farmers in Central Region of Ghana. American Journal of Experimental Agriculture, 3, 277-292.

\section{BATEMAN, R. 2009. Pesticide Use in Cocoa: A Guide for Training Administrative and} Research Staff, London, ICCO.

DORMON, E. N. A., VAN HUIS, A. \& LEEUWIS, C. 2007. Effectiveness and profitability of integrated pest management for improving yield on smallholder cocoa farms in Ghana. International Journal of Tropical Insect Science, 27, 2739.

DUNN, J. A. 1963. The resistance pattern in a strain of the cocoa capsid (Distantiella theobroma Dist.) resistant to BHC. Entomologia Experimentalis et Applicata, 6, 304-308.

EGUAGIE, W. E. 1973. Field susceptibility of the cocoa mirid, Sahlbergella singularis Haglund (heteroptera) to some new insecticides. Pesticide Science, 4, 273-282.

ENTWISTLE, P. F. 1975. Insects and cocoa. In: WOOD, G. A. R. (ed.) Cocoa. 3rd ed.: Longman Group Limited. 163-191.

ENTWISTLE, P. F., JOHNSON, C. G. \& DUNN, E. 1959. New pests of cocoa (Theobroma cacao L.) in Ghana following applications of insecticides. Nature, 184, 2040-2040.

GERKEN, A., SUGLO, J. \& BRAUN, M. 2001. Integrated Crop Protection Project and Ministry of Agriculture, In: CROP PROTECTION POLICY IN GHANA (ed.). Pokoase, Accra.

GOVERNMENT OF GHANA. 2011. COCOBOD Inaugurates National Steering Committee [Online]. Accra: Government of Ghana. Available: http://www.ghana.gov.gh/index.php/news/general-news/5088-cocobodinaugurates-national-steering-committee [Accessed 5th June 2012].

ICCO. 2012/13. Annual Report [Online]. International cocoa organization. Available: www.icco.org/about-us/international-cocoa-agreements/cat_view/1-annualreport.html [Accessed 8th January 2015.

JUST, D. \& ZILBERMAN, D. 2002. "Information Systems in Agriculture". Giannini Foundation of Agricultural Economics, 6 (1) September/October 2002 (www.agecon.ucdavis.edu/outreach/update_articles/v6n1_2.pdf).

KUMI, E. \& DAYMOND, A. J. 2015. Farmers' perceptions of the effectiveness of the Cocoa Disease and Pest Control Programme (CODEPEC) in Ghana and its effects on poverty reduction. American Journal of Experimental Agriculture. In Press.

MATTHEWS, G., WILES, T. \& BALEGUEL, P. 2003. A survey of pesticide application in Cameroon. Crop Protection, 22, 707-714.

MUNSHI, K. 2002. Social learning in a heterogeneous population: Technology diffusion in the Indian green revolution. Mimeo: University of Pennsylvania.

ODAME, H. H. \& KASSAM, A. 2002. Listening to stakeholders: Agricultural research and radio linkages. ISNAR Briefing Paper 48. The Hague, ISNAR. 
OLUJIDE, M. G. \& ADEOGUN, S. O. 2006. Assessment of cocoa growers' farm management practices in Ondo State, Nigeria. Spanish Journal of Agriculture, 4, 173-179.

OWUSU-ANSAH, E., KORANTENG-ADDO, J. E., BOAMPONSEM, L. K., MENLAH, E. \& ABOLE, E. 2010. Assessment of Lindane pesticide residue in cocoa beans in the Twifo Praso district of Ghana. Journal of Chemical and Pharmaceutical Research, 2, 580-587.

OWUSU-MANU, E. 1995. The need for chemical control of cocoa mirids in Ghana. Cocoa Pests and Diseases Seminar. Accra, Ghana.

PADI, B. 1997. Prospects for the control of cocoa capsids - Alternatives to chemical control. Proceedings of the 1st International Cocoa Pests and Diseases Seminar, pp 28-36. Accra, Ghana.

PADI, B. \& OWUSU, J. K. 1998. Towards an integrated pest management for sustainable cocoa production in Ghana. Workshop. Panama, Smithsonian Institution, Washington, D.C.

POMP, M. \& BURGER, K. 1995. Innovation and imitation: Adoption of cocoa by Indonesian smallholders. World Development, 23, 423-431.

PRINS, G. 1965. Contact toxicities of 22 insecticides to the cocoa mirid Distantiella theobroma (Dist.) (Hemiptera, Miridae). Bulletin of Entomological Research, 56, 231-235.

RAW, F. 1959. Studies on the chemical control of cacao mirids, Distantiella theobroma (Dist.) and Sahlbergella singularis Hagl. Bulletin of Entomological Research, 50, 13-23.

REJESUS, R. M., PALIS, F. G., LAPITAN, A. V., TRUONG THI NGOC, C. \& HOSSAIN, M. 2009. The impact of integrated pest management information dissemination methods on insecticide use and efficiency: Evidence from rice producers in South Vietnam. Review of Agricultural Economics, 31, 814-833.

SONWA, D. J., COULIBALY, O., WEISE, S. F., AKINWUMI ADESINA, A. \& JANSSENS, M. J. J. 2008. Management of cocoa: Constraints during acquisition and application of pesticides in the humid forest zones of southern Cameroon. Crop Protection, 27, 1159-1164. 
1 Table 1: Farmer and farm characteristics: Frequency distribution

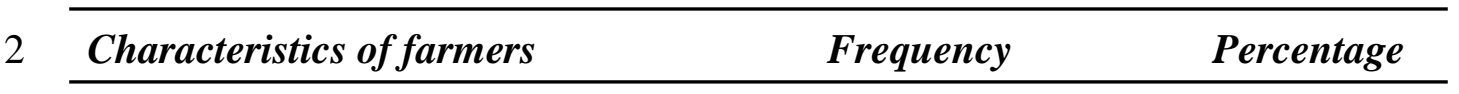

Age (years)

$20-40$

$41-60$

143

$>60$

86

31

Total

280

100

Marital status

Single

12

4

Married

229

82

Divorced

9

3

Widow

20

7

Widower

10

4

Total

280

100

Farm ownership status

Owner

Share cropper (Abunu)

20

7.1

Share cropper (Abusa)

15

5.4

Share cropper (Abunan)

1

0.4

Total

280

100

Numbers of cocoa farms operated

$>6$ 
Farm age (years)

1-10 94

33.6

11-20

115

41.1

21-30

49

17.5

$>30$

22

7.8

Total

280

100

Farm size

(hectares)

$<1.5$

196

70

1.5-3

64

22.9

3-5

14

5

$>5$

6

2.1

Total

280

100

1 NB: Definition of Share cropper (Abunu, Abusa and Abunan): Proceeds from the farm

2 are shared between caretaker and landlord with the caretaker getting 75\% (Abusa), 50\%

3 (Abunu) or $25 \%$ (Abunan).

4

5

6

7

8

9

10 
1 Table 2: Issues that informed farmer's choice of the month to start insecticide

2 application

\begin{tabular}{|c|c|c|}
\hline Issues & Frequency & Percent \\
\hline Start of the CODAPEC programme & 127 & 49.2 \\
\hline Presence of mirids & 50 & 19.4 \\
\hline Weather & 26 & 10.1 \\
\hline CRIC recommendation & 17 & 6.6 \\
\hline \multicolumn{3}{|l|}{ Availability of inputs and } \\
\hline machines & 16 & 6.1 \\
\hline Level of damage & 14 & 5.4 \\
\hline Availability of Neem & 2 & 0.8 \\
\hline Production of pods & 2 & 0.8 \\
\hline Another farmer/relative & 1 & 0.4 \\
\hline Extension officer's advice & 1 & 0.4 \\
\hline Previous yield losses in bags & 1 & 0.4 \\
\hline Appearance of flowers & 1 & 0.4 \\
\hline Total & 258 & 100.0 \\
\hline
\end{tabular}

3

4

5

6

7

8

9

10 
1 Table 3: Farmers' source of information on insecticide usage: Frequency distribution

2

\begin{tabular}{lcr} 
Insecticide usage & Frequency & Percentag \\
\hline Ability to access information on insecticide to use & & \\
Yes & 122 & 43.6 \\
No & 158 & 56.4 \\
Total & & $\mathbf{1 0 0}$
\end{tabular}

Source of information on insecticide to use

Extension Officers 104

Certification Officers

6

CRIG

5

Chemical and input sellers

Other farmers

Total

Ability to access to information on time of application

Yes

122

No

158

56.4

Total

280

100

Source of information on time of application

Extension Officers

105

86.1

Certification Officers

7

CRIG

4

Chemical and input sellers

4

Other farmers

2

1.6

Total

122

100 
Access to information on frequency of application

No

Total

Access to information on frequency of application

Extension Officers

86.1

Certification Officers

CRIG

Chemical and input sellers

Other farmers

Total

Frequency of receipt of information per year

Once

Twice

Three times

Four times

$>$ Four times 
1 Table 4: Farmers' preference for medium of information transfer

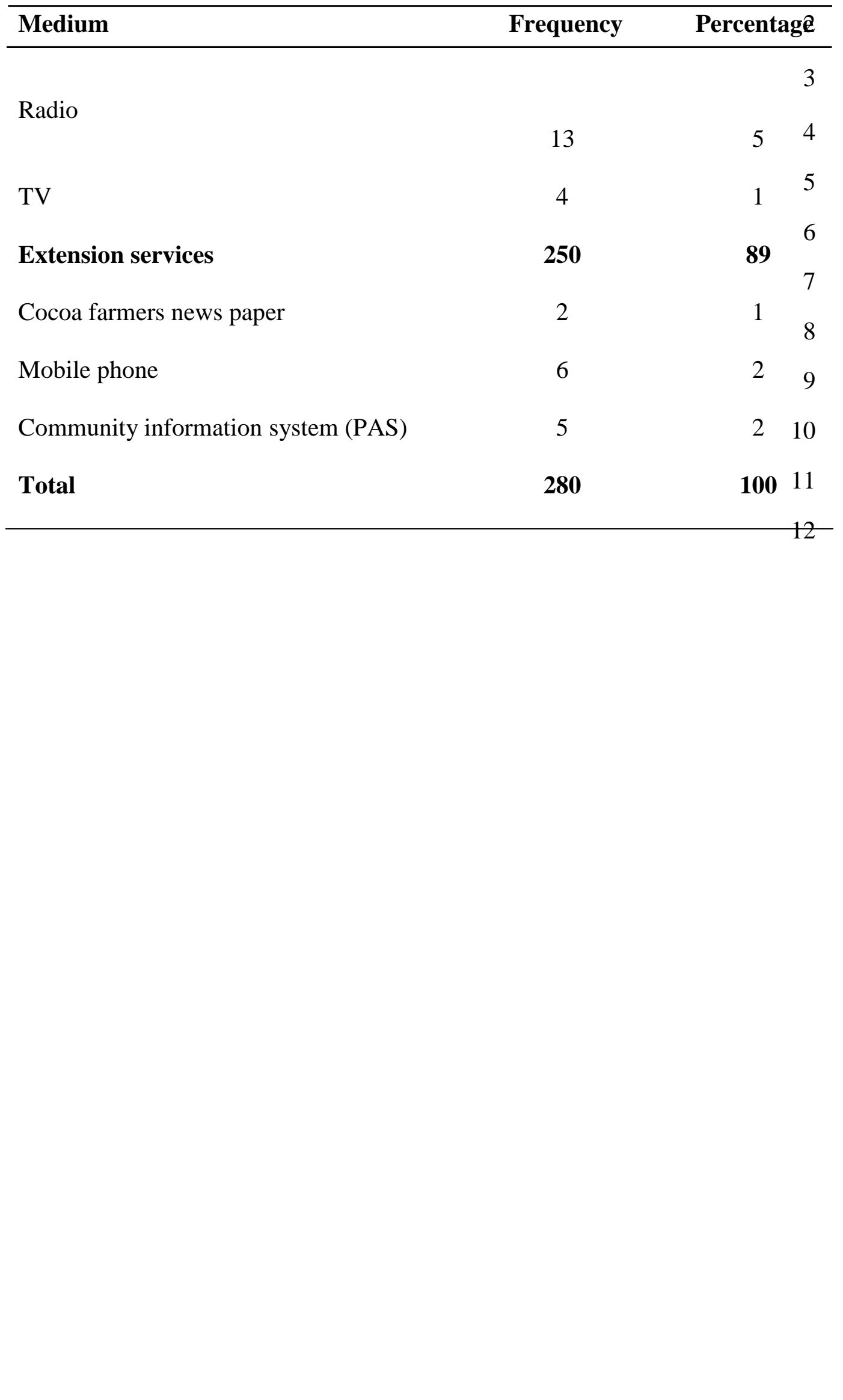




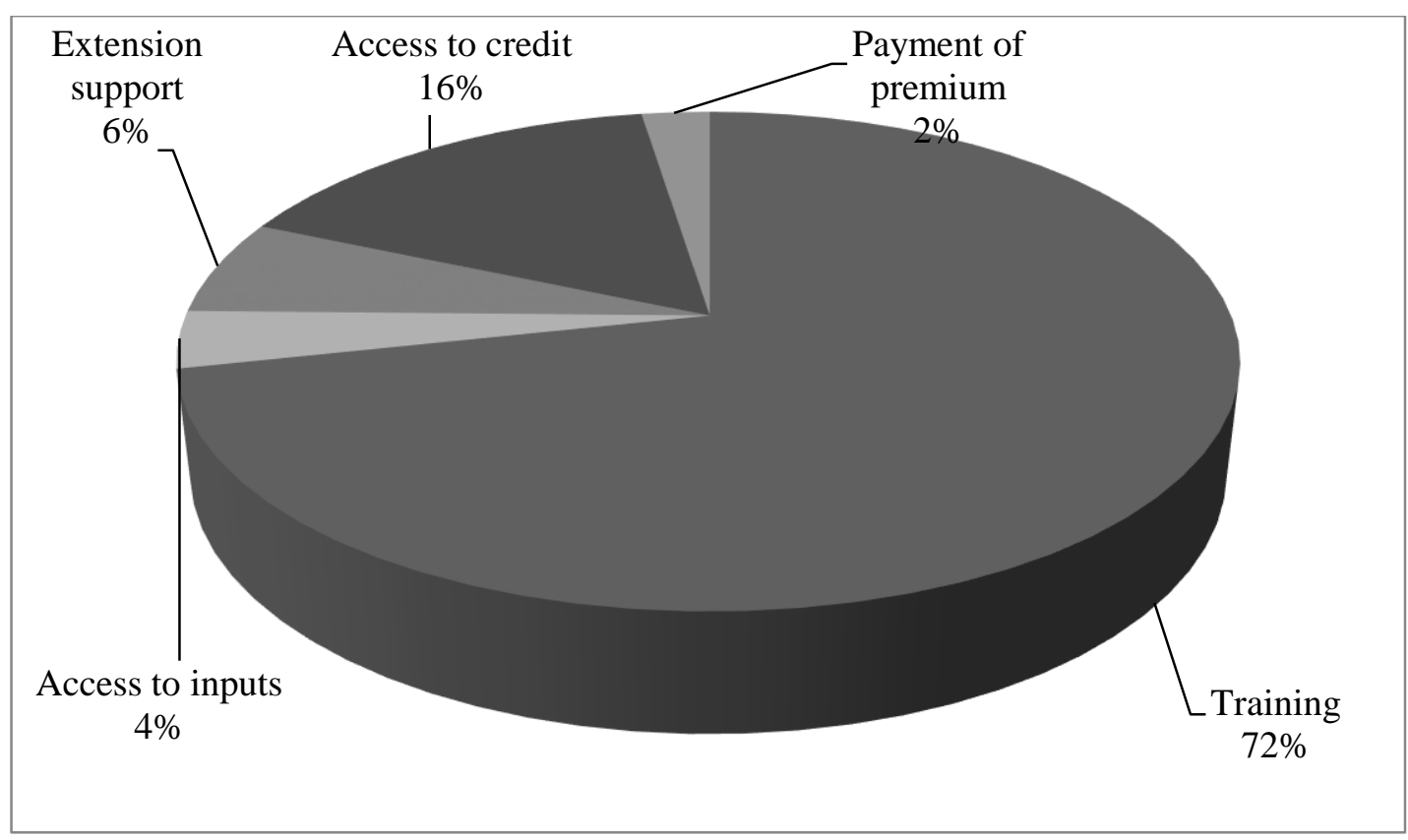

2

Figure 1: Farmers' motivation for joining farmer associations $(n=81)$

3

4

5

6

7

8

9

10

11

12

13

14

15 


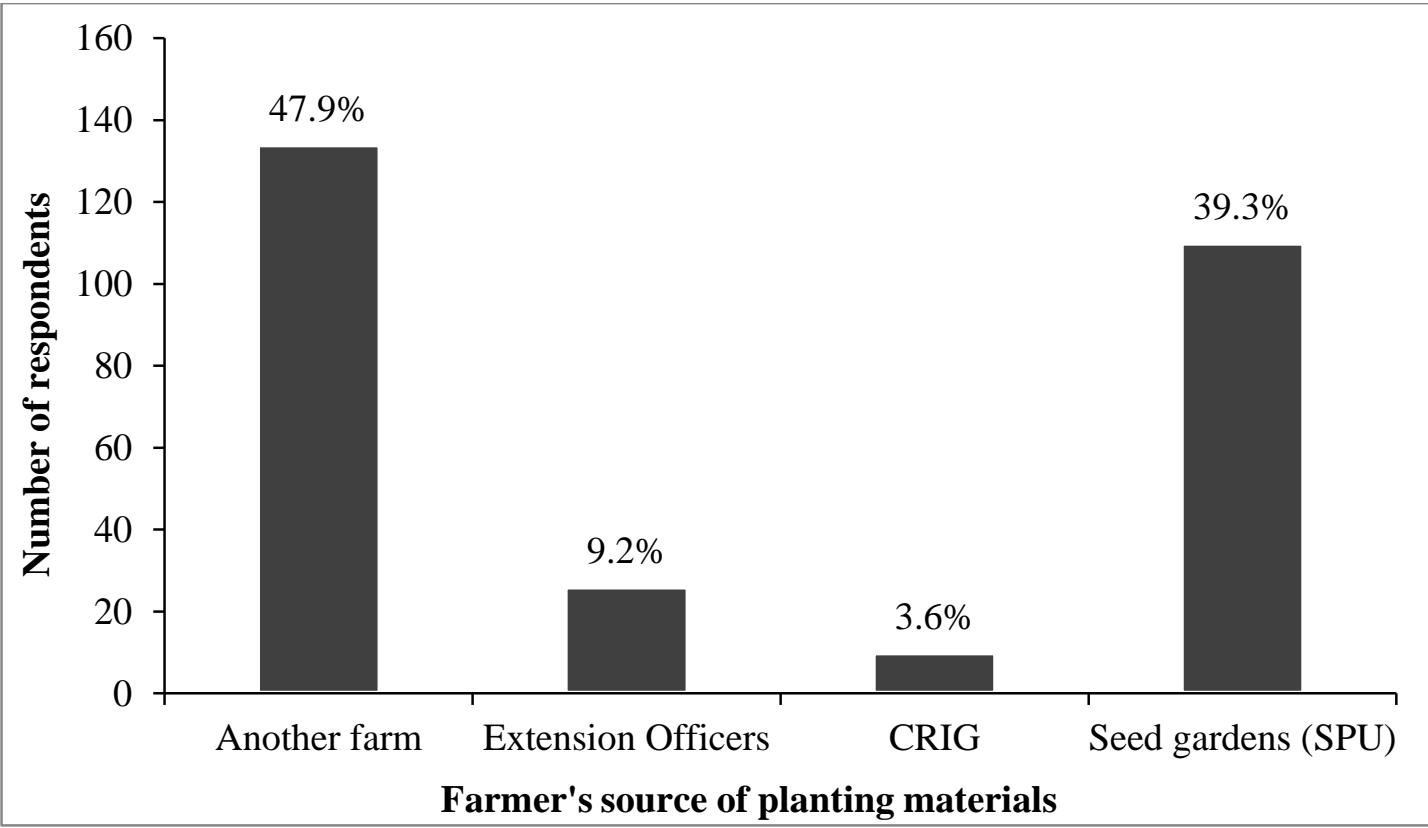

2

Figure 2: Farmers' source of planting materials $(\mathrm{n}=280)$

3

4

5

6

7

8

9

10

11

12

13 


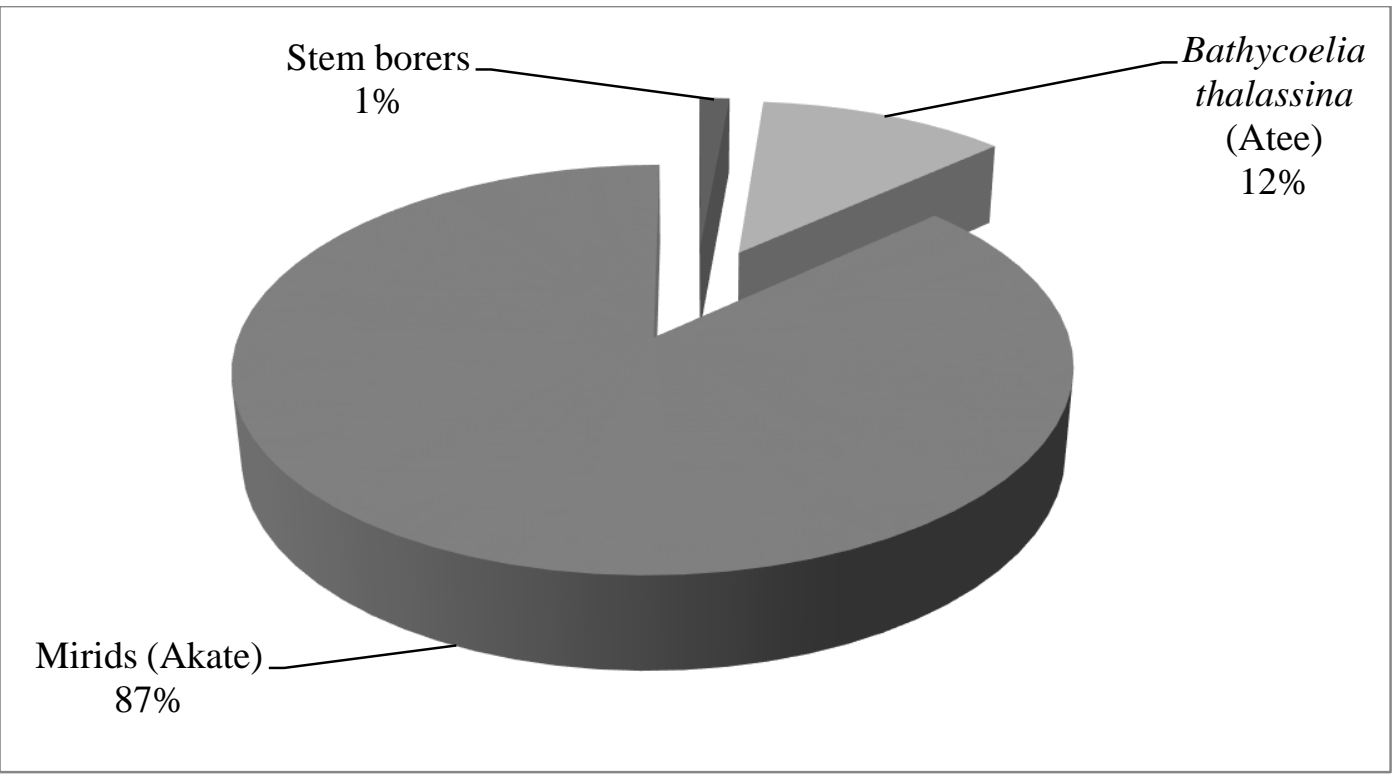

2

Figure 3: Farmers' perception of the group of pests that they consider to be most economically important $(n=280)$

4

5

6

7

8

9

10

11

12

13

14

15

16

17 


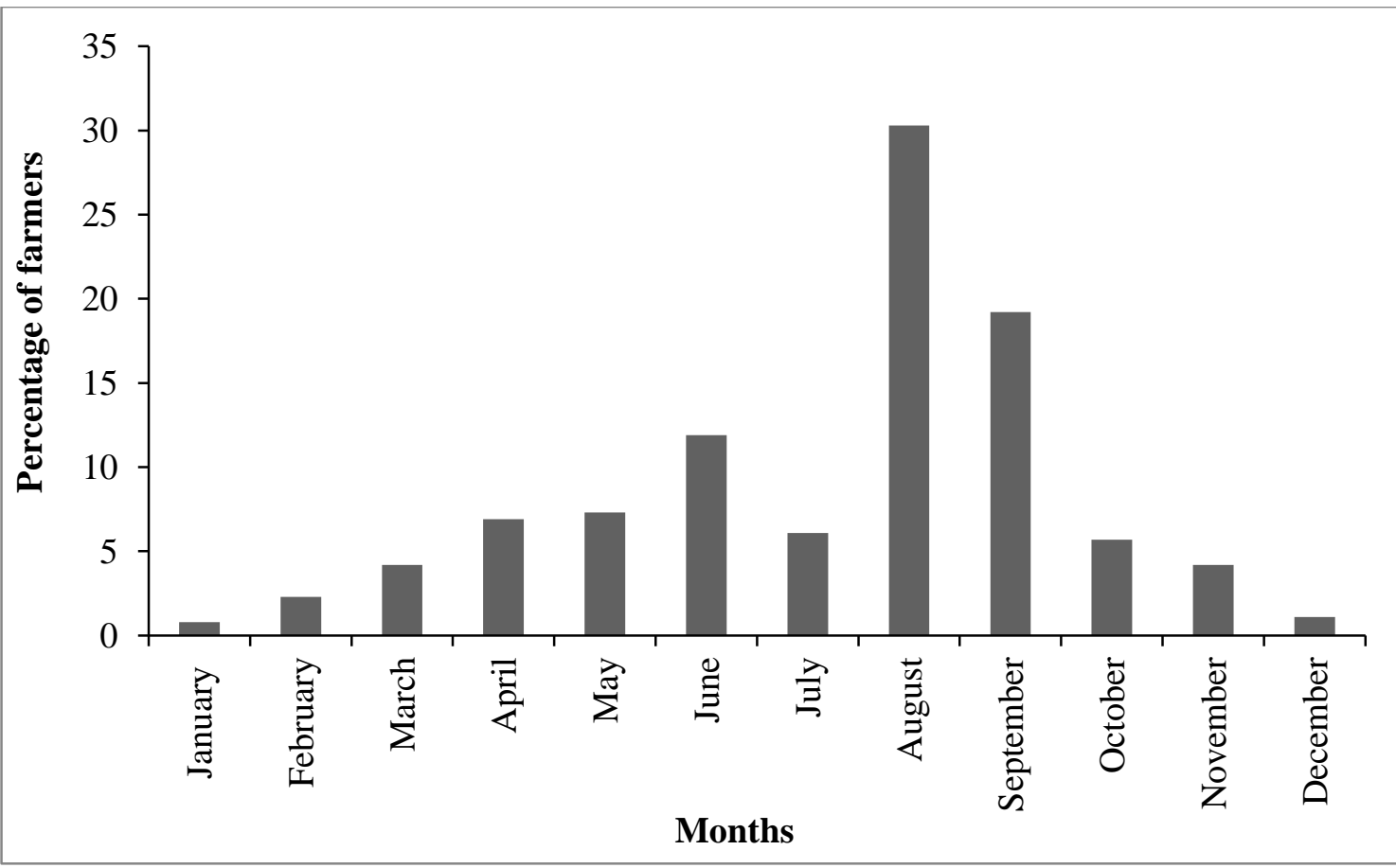

2

Figure 4: Frequency distribution of month in which respondents first applied insecticides $(n=261)$

4

5

6

7 